\title{
Efficiency Analysis of Large Global Manufacturing Companies by Data Envelopment Analysis Approach
}

\author{
Thi Kim Lien Nguyen ${ }^{1,2^{*}}$ and Hong Huyen $\mathrm{Le}^{2}$ \\ ${ }^{1}$ Scientific Research-International Cooperation, Thanh Dong University, Hai Duong, Hai Duong Province 171960. \\ ${ }^{2}$ Department of Economics-Business Administration, Thanh Dong University, Hai Duong, Hai Duong Province 171960, Vietnam
}

\begin{abstract}
The development process of the manufacturing industry is a foundation for establishing many large enterprises around the world. The purpose of this study measures the performance of eight large manufacturing companies from past to future by a data envelopment analysis (DEA) approach. First, the super-SBM model was used to calculate the efficiency score in the previous term. Second, the resampling model with Lucas and weights applies to compute the forecasting values based on the historical data from 2016 to 2020; notably, this model can calculate the efficiency score in the future period of 2021-2025, based on integrating super-efficiency. The empirical results of the past, current, and estimated scores reveal that Toyota, Apple, Samsung, Honda, and Cardinal always obtain the performance above one number. Whereas Cardinal is the best manufacturing company with a consistently high score based on the efficiency qualification in the whole term, Ford is the worst manufacturing company as its efficiency score under one number. Finding results figure out an overall picture of the operational process of large manufacturing companies. The analysis result suggests a direction for improving the inefficient cases in future terms.
\end{abstract}

Keywords: Manufacturing company; data envelopment analysis; super-SBM model; resampling model; efficiency.

JEL Classification: C81- Methodology for Collecting, Estimating, and Organizing Microeconomic Data; G17 - Financial Forecasting and Simulation; L60- General.

\section{INTRODUCTION}

Customer demand for new products is an important lever to enhance the transformation of goods, materials, and substances into new products. The manufacturers must have plants to transform materials into finished goods before the goods are produced for public consumption, manufacturers research to improve productivity and meet customer requirements (Fajsi et al., 2017). Technological development has directly affected innovating adaptable manufacturing and business models and creating new strategies (David et al., 2015). Chen et al., (2020) showed the positive and negative effects of digitalisation in manufacturing. Zhang and Lee (2021) investigated the 317 listed enterprises of the intelligent manufacturing industries in China. The analysis results discovered their good financial performance when these enterprises effort innovation and investment in research and development. The application of industry 4.0 technology is a workable alternative to increase the performance of sustainable manufacturing (Enyoghasi \& Badurdeen, 2021). By the way, large manufacturing companies maintain and develop based on the development of science and technology.

Many researchers studied and published papers in the manufacturing industry by using many methods. For instance, Lia (2011) used endogenous growth theory and Feder's two-sec

\footnotetext{
*Address correspondence to this author at Scientific Research-International Cooperation, Thanh Dong University, Hai Duong, Hai Duong Province 171960. Mobile: +84366449688; E-mail: lienntk@thanhdong.edu.vn
}

tor model to analyse the influence of producer service on the upgrading of the manufacturing industry in China. Chen et al., (2018) explored the nonmonotonic relationship between market structure and total factor productivity in the United States manufacturing industry by the novel panel GMM model. Dwivedi et al., (2019) applied Kappa analysis, consensus building, and total interpretive structural modelling to evaluate the sustainable manufacturing policies of the leather industry in India. Le (2020) determined the effects of sustainable supply chain management with environmental management accounting, financial and environmental efficiency to the Vietnamese construction materials manufacturing industry. AlQershi et al., (2021) applied the Partial Least SquaresStructural Equation Modelling to seek the effect of strategic innovation in manufacturing and small and medium-sized enterprises in Yemen. In this study, we use the super-SBM and resampling models in the DEA method for evaluating the performance of global large manufacturing companies.

DEA is a statistics method with a non-parametric approach to present the relationship between inputs and outputs with the minimum assumptions (Banker et al., 1984). This method is used to evaluate the efficiency of the decision-making unit (DMU). The studied aspects of efficiency that have applied this method, including sport (Kern et al., 2012), energy (Tu, 2015), pharmaceutical (Alam \& Rastgi, 2019), transportation (Shen et al., 2020), etc. The efficiency score can be conducted by the ratio between input variables and output variables under the condition of constant return to scale. Although the DEA method has lots of different models, including CCR, 
$\mathrm{BBC}$, and $\mathrm{EBM}$ for solving and presenting the various inputs and outputs, the performance has two classifications with efficiency score from 0 to 1 ; super-SBM, resampling, and negative super-SBM max with efficiency score from 0 to $\infty$. Therefore, the models with the limited scores in the efficient cases, as one number cannot identify the efficiency level, the model with the scores above one number in the efficient cases can determine the efficiency level for all efficient DMUs. In this study, we focus on the manufacturing industry by using the super-SBM and resampling model.

Tone (2002) proposed the super-SBM model to solve slacks in inputs/ outputs and compare amongst DMUs with the radial measure of super-efficiency. This model can compute the efficiency scores with different classifications for all DMUs in the same period; moreover, it can measure the efficiency when dealing with undesirable variables or negative values. For example, Feng et al., (2018) used the super-SBM model to evaluate the green innovation performance in China's manufacturing industry. Huang and Liu (2020) found the efficiency of coal-based hydrogen production, renewable hydrogen production, and the integrated scheme by combining the super-SBM model and undesirable outputs. Nguyen et al. (2021) determined the performance of Vietnamese securities companies via the negative super-SBM model. Therefore, the super-SBM model has not only applied various aspects but also integrated with different contexts. This study combines the super-SBM model in the resampling to conduct future efficiency.

The resampling model with the variations via the confidence intervals of DEA scores proposed by Tone and Ouenniche (2016), which uses to predict future efficiency. Wang and Le (2018) combined gauge and forecast to deal with the macroeconomic performance problem of developed countries and developing countries in Asia by using two variants of the resampling model, including past-present and past-present-future. Hsieh et al., (2019) recommended a suggestion for China's regional government to be adjusted the water resource distribution of each region after evaluating water resources' use efficiency. Wang et al. (2021) used the resampling pastpresent-future model for predicting the efficiency of the IC packaging and testing industry.

Therefore, the super-SBM model is a good measurement model to distinguish the efficiency level; the resampling model is an excellent tool to forecast future efficiency. In this study, the purpose is to reckon out the efficiency of 8 large manufacturing companies from past to future. First, the superSBM model is employed to calculate the efficiency score from 2016 to 2020 . Second, the resampling model is applied to predict the future efficiency from 2021 to 2025 . The empirical results reveal the performance of all companies and discover efficient and inefficient companies in whole terms. The research recommends an overall picture of the operational process in the manufacturing industry.

The study organizes as follows: Section 1 introduces the aim of this study and gives the theoretical research of manufacturing industry, DEA, super-SBM model, and resampling model; Section 2 shows the source of data and provides the mathematical equation of super-SBM and resampling models; Section 3 conducts the empirical results; Section 4 provides the contribution and implications of this study; Section 5 summarises the main findings, limitations, and future researches.

\section{MATERIALS AND METHODS}

\subsection{Data Collection}

The manufacturing industry implements the fabrication and processing of products, including foods, chemicals, textiles, machines, and equipment from raw materials and commodities. With the purpose of evaluation for the manufacturing industry, the study selects eight large manufacturing companies from Manufacturing (Freeman, 2020), as shown in Table 1.

Table 1. Name of Eight Large Manufacturing Companies.

\begin{tabular}{|c|c|c|}
\hline Name & Abbreviation & Headquarter \\
\hline Volkswagen AG & $\mathrm{DMU}_{1}$ & Germany \\
\hline Toyota Motor Corporation & $\mathrm{DMU}_{2}$ & Japan \\
\hline Apple & $\mathrm{DMU}_{3}$ & United State \\
\hline Samsung & $\mathrm{DMU}_{4}$ & Korea \\
\hline Daimler AG & $\mathrm{DMU}_{5}$ & Germany \\
\hline General Motors & $\mathrm{DMU}_{6}$ & United State \\
\hline Honda Motor Company & $\mathrm{DMU}_{7}$ & Japan \\
\hline Cardinal Health & $\mathrm{DMU}_{8}$ & United State \\
\hline
\end{tabular}

Source: Freeman (2020)

Based on the principle of DEA, the input and output variables reflect the business performance with the appreciated ratio among variables and number of DMUs; thus, the study chooses the appreciated factors in financial reports to predict and determine the efficiency of large manufacturing companies over the world.

\section{Input Factors}

Total assets (TA): Total amount of assets of an enterprise.

Cost of revenue (CR): Total cost that an enterprise manufactures and delivers a product to customers.

Operating expense (OE): The expenses of an enterprise occur in the normal business operation.

\section{Output Factors}

Operating revenue (OR): The revenue of an enterprise that receives from the primary business activities.

Gross profit (GP): The profit of a company by deducting the costs that relate to making products.

The above factors are meaningful values in a financial statement to evaluate an operational business. The study gathered the actual data of these companies between 2016 and 2020 from Tmxmoney (2021), as shown in Table 2, which used to measure the efficiency in the previous time and forecast future situations.

The descriptive statistics of the inputs and outputs of eight manufacturing companies are summarised, as shown in Table 2. The average values of total assets described a growing trend year by year from 2016 to 2020 ; the average values of gross profits described a developing trend year by year from 2016 to 2018 and a decreasing trend from 2019 to 2020 . These values present the changes of all large manufacturing companies 
in previous different periods. Hence, the resampling model in the DEA method is used to analyse the efficiency scores of these manufacturing companies in future periods.

Table 2. Summarize the Collected Data.

\begin{tabular}{|c|c|c|c|c|c|c|}
\hline Index & Year & (I)TA & (I)CR & (I)OE & (O)OR & (O)GP \\
\hline Max & \multirow{4}{*}{2016} & 443068 & 207545 & 46408 & 265341 & 84263 \\
\hline Min & & 34122 & 104045 & 4107 & 121546 & 6543 \\
\hline Average & & 244254 & 133823 & 24188 & 177593 & 42702 \\
\hline SD & & 110788 & 30908 & 10810 & 43052 & 24175 \\
\hline Max & \multirow{4}{*}{2017} & 455423 & 208728 & 50212 & 257812 & 97769 \\
\hline Min & & 40112 & 99761 & 4302 & 129976 & 6544 \\
\hline Average & & 261766 & 137393 & 23263 & 182544 & 44061 \\
\hline SD & & 117939 & 31016 & 12840 & 45334 & 30576 \\
\hline Max & \multirow{4}{*}{2018} & 469979 & 219331 & 46533 & 274463 & 101839 \\
\hline Min & & 39951 & 110180 & 5303 & 136809 & 7181 \\
\hline Average & & 272560 & 145986 & 24187 & 193191 & 46056 \\
\hline SD & & 121321 & 32744 & 12035 & 51600 & 33882 \\
\hline Max & \multirow{4}{*}{2019} & 485194 & 227526 & 49107 & 282368 & 98392 \\
\hline Min & & 40963 & 115508 & 5101 & 137237 & 6834 \\
\hline Average & & 277373 & 150164 & 25000 & 192756 & 41379 \\
\hline SD & & 123453 & 34036 & 13205 & 51938 & 29340 \\
\hline Max & \multirow{4}{*}{2020} & 492140 & 225144 & 49933 & 279605 & 104956 \\
\hline Min & & 40766 & 108812 & 5096 & 122485 & 6868 \\
\hline Average & & 278752 & 143863 & 24188 & 186503 & 41481 \\
\hline SD & & 123191 & 37195 & 14030 & 59080 & 33015 \\
\hline
\end{tabular}

Source: Vietstock (2021).

\subsection{Method}

Data envelopment analysis has different models to deal with multiple inputs and outputs, which apply to calculate the efficiency score in various aspects in many contexts. Charnes, Cooper, and Rhodes (1978) introduced the first model calling the CCR model, which applies to measure the efficiency score of a decision-making unit (DMU) based on a linear programming problem. DEA has been developed for over forty years; therefore, it has had many models to deal with desirable and undesirable inputs and outputs, calculate the maximum efficiency score above one number, and predict the future value. For observing the operational process between historical and future periods, this study chooses the super SBM and resampling models to estimate the efficiency scores of manufacturing companies from past to future.

\section{Super Slacked-based Measure Model}

The super-SBM model is used to evaluate the efficiency of companies. This model presents the super efficiency by the relative efficiency (Andersen and Petersen, 1993) when dealing with multiple inputs to produce multiple outputs (Färe and
Lovell, 1978). Tone (2002) officially introduced the super slacked-based measure (Super-SBM) model to compute super-efficiency. In this study, the super-SBM model deals $n$ DMUs with inputs (a) and outputs (b), a and b are positive values. The production possibility is determined as follows:

$P=(a, b)$

The efficiency of one DMU is calculated following:

$\min p=\frac{1-\frac{1}{n} \sum_{i=1}^{n} s_{i}^{-} / a_{i 0}}{1-\frac{1}{s} \sum_{i=1}^{s} s_{i}^{-} / b_{i 0}}$

$\left(s^{-}>0 ; s^{+}>0\right)$

Setting up the optimal solutions for the SBM model, the DMU will have efficiency when $\mathrm{p}^{*}, \mathrm{~s}^{*}$, and $\mathrm{s}^{*}$ are equal to zero. Here, there is no input excess and output shortfall; thus, the equation of the super-SBM model is identified by:

$$
\begin{aligned}
& \min p=\frac{\frac{1}{n} \sum_{i=1}^{n} \overline{a_{i}} / a_{i 0}}{\frac{1}{s} \sum_{i=1}^{s} \bar{b}_{i} / b_{i 0}} \\
& \left(\bar{a} \geq a_{0} ; \bar{b} \leq b ; \bar{a} \& \bar{b}>0 ; \lambda>0\right)
\end{aligned}
$$

If the score of DMU is lower than one number, it does not have efficiency. If the score of DMU is equal to or higher than one number, it will have efficiency. In inefficient cases, the input factors should reduce excesses, and the output factors should increase the shortage.

\section{Resampling Model}

The resampling model differs from other models because it can evaluate the performance of DMU and forecast future values based on the resampling approach. Therefore, this model is a combination of other models in the DEA method and other forecasting models that Tone (2016) proposed to estimate the confidence interval of the DEA score over the past and present time, then future time. We let the historical set of input and output matrix be $\left(X^{t}, Y^{t}\right)(t=1, \ldots T)$ and the number of DMU be $n$. Where $t=1$ is the first period and $t=T$ is the last period with $X^{t}=\left(X_{1}^{t}, \ldots, X_{n}^{t}\right)$ and $Y^{t}=\left(Y_{1}^{t}, \ldots, Y_{n}^{t}\right)$.

First, the super-efficiency is used to measure the efficiency score of the last period's DMUs, then the confidence interval with replicas $\left(X^{t}, Y^{t}\right)(t=1, \ldots T)$ is gauged in the next step.

Second, we let the weight be ${ }^{w_{t}}$ to the period ${ }^{t}$ with an assumption. Thus, the following Lucas number series $\left(l_{1}, \ldots, l_{t}\right)_{\text {is }}$ a candidate, the weight is identified by:

$w_{t}=\frac{l_{t}}{L}(t=1, \ldots, T)$

Subject to 


$$
\begin{aligned}
& L=\sum_{t=1}^{T} l_{t} \\
& l_{t+2}=l_{t}+l_{t+1}\left(t=1, \ldots T-2 ; l_{1}=1, l_{2}=2\right)
\end{aligned}
$$

Third, from the last period's score, the prediction for the future, namely, $\left(X^{t+1}, Y^{t+1}\right)(t=1, \ldots T)$ is computed for all DMUs based on the historical data $\left(X^{t}, Y^{t}\right)(t=1, \ldots T)$. The forecasted efficiency scores are measured by using the historical data and their confidence intervals. In this study, we approach the scenario of Lucas weight with the super-efficiency for future DMU $\left(X^{t+1}, Y^{t+1}\right)$ when using the historical data set $\left(X^{t}, Y^{t}\right)(t=1, \ldots T)$.

For the resampling model, the forecasted data needs to use replicas of historical data to seek features of datasets. The replicas of datasets will be rejected and retest when they are not representative of the datasets.

Finally, to ensure the accuracy of future data, we use the mean absolute percentage error (MAPE) to check. The mathematical equation of MAPE is calculated:

$$
M A P E=\frac{1}{4} \sum_{t=1}^{4}\left|\frac{A_{t}-F_{t}}{A_{t}}\right|
$$

Whereas, At: actual value; Ft: forecasted value.

If the MAPE of DMUs is higher than $50 \%$, they must remove and other forecasting models such as holt winters methods will be used to estimate future data again. All forecasted data are accepted when the MAPE is lower than 50\%, these efficiency scores represent the future efficiency scores of manufacturing companies from 2021 to 2024.

\section{EMPIRICAL RESULTS}

\subsection{Historical Efficiency}

In the past, the manufacturing industry did not develop sharply in global and most countries contributed to agriculture. Nowadays, it expands sharply, which creates many large manufacturing companies around the world. From the collected data of 8 large manufacturing companies from 2016 to 2020, as shown in Table 2, this study proposed the super-SBM model in the DEA method to escalate their efficiency scores.

In the DEA method, these collected data must check the Pearson correlation coefficient to ensure the isotonic relationship between input and input; output and output; and, input and output before computing the performance. The relationship among factors is accepted when the Pearson correlation is from -1 to +1 , it is divided into four classifications, including a perfect linear relation as near to $\pm \mathbf{1}$; a strong correlation as near to \pm 0.5 and \pm 0.8 ; a medium correlation as near to \pm 0.3 and \pm 0.49 ; a low correlation with the lower than \pm 0.29 . As shown in Table A, the Pearson correlation in historical time was from -0.015 to 1 ; hence, these data had an appreciated relationship. All collected data are suitable to escalate the performance via the super-SBM model and the efficiency scores for all DMUs in historical terms, as shown in Table 3.
Table 3. Historical Efficiency.

\begin{tabular}{|c|c|c|c|c|c|c|}
\hline DMUs & $\mathbf{2 0 1 6}$ & $\mathbf{2 0 1 7}$ & $\mathbf{2 0 1 8}$ & $\mathbf{2 0 1 9}$ & $\mathbf{2 0 2 0}$ & Average \\
\hline $\mathrm{DMU}_{1}$ & 1.0000 & 1.0006 & 1.0239 & 1.0798 & 1.1320 & 1.0473 \\
\hline $\mathrm{DMU}_{2}$ & 1.2391 & 1.2008 & 1.0922 & 1.1635 & 1.0957 & 1.1583 \\
\hline $\mathrm{DMU}_{3}$ & 1.3737 & 1.2152 & 1.2081 & 1.1115 & 1.1221 & 1.2061 \\
\hline $\mathrm{DMU}_{4}$ & 0.7949 & 0.8338 & 0.7262 & 0.7145 & 0.6485 & 0.7436 \\
\hline $\mathrm{DMU}_{5}$ & 0.7802 & 0.7477 & 0.6820 & 1.3852 & 1.4944 & 1.0179 \\
\hline $\mathrm{DMU}_{6}$ & 0.6624 & 0.6621 & 0.6211 & 0.6749 & 0.7380 & 0.6717 \\
\hline $\mathrm{DMU}_{7}$ & 1.0315 & 1.0728 & 1.0431 & 1.0469 & 1.0700 & 1.0529 \\
\hline $\mathrm{DMU}_{8}$ & 4.1172 & 2.8512 & 2.8453 & 3.2405 & 3.8220 & 3.3752 \\
\hline
\end{tabular}

Observing Table $\mathbf{3}$, the efficiency scores of all manufacturing companies fluctuated year by year. Five companies, including DMU1, DMU2, DMU3, DMU7, and DMU8, obtained the efficiency when their efficiency scores were higher than one number in whole terms. Whereas DMU8 had a sharp variation when its score reduced from 4.1172 in 2016 to 2.8512 in 2017, then increased smoothly in next years; remaining companies had a smooth change. DMU5 was a unique company, which had both efficiency and inefficiency, and it also exhibited a dramatic efficiency up and then down smoothly according to each year during the period 2016-2020. Besides, DMU4 and DMU6 did not achieve efficiency when their scores were always less than one number in the whole term.

The average efficiency of these manufacturing companies shows that the best average value was DMU8, as its efficiency scores always obtained the highest values year by year from 2016 to 2020. DMU6 and DMU7 had efficiency scores less than one number, but the lowest average value was DMU6 as its efficiency scores during the period 2016-2020 were $0.6624 ; 0.6621 ; 0.6211 ; 0.6749 ; 0.738$, respectively. This company was relatively poor; thus, it should have more effective investment strategies to improve operational efficiency. The efficiency score of the remaining DMUs obtained the performance level with the average score from 1.0179 to 1.2061. As a result, the empirical analysis result discovered six average efficient scores, including DMU1; DMU2; DMU3; DMU5; DMU7; and DMU8, and two average inefficient scores, including DMU4 and DMU6.

\subsection{Future Efficiency}

Based on the principle of the resampling model in DEA, this research used the historical data from 2016 to 2019 to escalate forecasted values in the next year. The efficiency scores of the year 2020 apply to compare the accuracy of the forecast model. Here, the research uses the different number of replicas to test the variation of scores so that these scores must check by increasing the number of replicas. Table 4 shows the results of the resampling model with 500 and 5000 replicas by Fisher 95\% confidence intervals approach for all DMUs to exhibit $97.5 \%$ and $2.5 \%$ confidence intervals and find no out-of-range samples. The difference among 500 replicas is less than 5000 replicas; thus, 500 replicas can be applied to compute the forecasted efficiency score. 
Table 4. Comparison between 500 and 5000 Replicas.

\begin{tabular}{|l|c|c|c|c|c|c|}
\hline \multirow{2}{*}{ DMUs } & \multicolumn{3}{|c|}{ 500 Replicas } & \multicolumn{3}{c|}{ 5000 Replicas } \\
\cline { 2 - 7 } & $\mathbf{9 7 . 5 0 \%}$ & DEA & $\mathbf{2 . 5 0 \%}$ & $\mathbf{9 7 . 5 0 \%}$ & DEA & $\mathbf{2 . 5 0 \%}$ \\
\hline $\mathrm{DMU}_{1}$ & 1.0844 & 1.0395 & 1.0000 & 1.0844 & 1.0395 & 1.0000 \\
\hline $\mathrm{DMU}_{2}$ & 1.2551 & 1.1116 & 1.0547 & 1.2593 & 1.1116 & 1.0567 \\
\hline $\mathrm{DMU}_{3}$ & 1.2853 & 1.1618 & 1.0718 & 1.2997 & 1.1618 & 1.0715 \\
\hline $\mathrm{DMU}_{4}$ & 0.8759 & 0.7416 & 0.6342 & 0.8852 & 0.7416 & 0.6290 \\
\hline $\mathrm{DMU}_{5}$ & 1.3894 & 0.9991 & 0.6295 & 1.3880 & 0.9991 & 0.6214 \\
\hline $\mathrm{DMU}_{6}$ & 0.8090 & 0.6343 & 0.5820 & 0.8074 & 0.6343 & 0.5796 \\
\hline $\mathrm{DMU}_{7}$ & 1.0984 & 1.0487 & 1.0174 & 1.0978 & 1.0487 & 1.0138 \\
\hline $\mathrm{DMU}_{8}$ & 3.7321 & 3.0143 & 2.7434 & 3.7528 & 3.0143 & 2.7670 \\
\hline
\end{tabular}

Also, to have more accuracy level, the forecasted values must check the difference between actual and forecasted efficiency scores and MAPEs, as shown in Table $\mathbf{5}$.

Table 5. Accuracy Test between Estimated and Actual Values in 2020.

\begin{tabular}{|c|c|c|c|c|}
\hline DMUs & Forecast & Actual & Difference & MAPE\% \\
\hline $\mathrm{DMU}_{1}$ & 1.0395 & 1.1320 & -0.0925 & 8.8985 \\
\hline $\mathrm{DMU}_{2}$ & 1.1116 & 1.0960 & 0.0159 & 1.4304 \\
\hline $\mathrm{DMU}_{3}$ & 1.1618 & 1.1220 & 0.0397 & 3.4171 \\
\hline $\mathrm{DMU}_{4}$ & 0.7416 & 0.6490 & 0.0931 & 12.5539 \\
\hline $\mathrm{DMU}_{5}$ & 0.9991 & 1.4940 & -0.4953 & 49.5746 \\
\hline $\mathrm{DMU}_{6}$ & 0.6343 & 0.7380 & -0.1037 & 16.3487 \\
\hline $\mathrm{DMU}_{7}$ & 1.0487 & 1.0700 & -0.0213 & 2.0311 \\
\hline $\mathrm{DMU}_{8}$ & 3.0143 & 3.8220 & -0.8077 & 26.7956 \\
\hline \multicolumn{5}{|c}{ Average MAPE\% } \\
\hline
\end{tabular}

Table 5 shows that the actual efficiency has a difference with the forecasted efficiency; whereas three DMUs, including DMU2, DMU3, and DMU4, have a positive difference with values 0.0159; 0.0397; and 0.0931, respectively; five DMUs, including DMU1, DMU5, DMU6, DMU7, and DMU8 get the negative difference with values $-0.0925 ;-0.4953$; -0.1037 ; 0.0213 ; and -0.8077 , respectively. Both positive and negative differences between actual and forecasted efficiency are less than one number. Besides, The MAPE tests the accuracy of the forecasted values. DMU5 has the highest value with $49.5746 \%$; however, it is still lower than 50\%; the MAPEs of remaining DMUs are less than $26.7956 \%$. The average MAPE for all DMUs is $15.1312 \%$, the predicted data achieve a standard qualification. As a result, the resampling model with 500 replicas is an appreciated model to estimate the future efficiency scores.

The forecasted values must check the correlation among variables as the historical data, the correlation of prediction data from 2021 to 2025, as shown in Table B. The correlation values in the future term are from 0.1648 to 1 ; thus, these values exhibit significant and positive correlations between input and input, output and output, and input and output. Therefore, these forecasted data are suitable to apply to the DEA method.

Future efficiency scores, as shown in Table 6, present a smooth fluctuation year by year. Six companies, including DMU1, DMU2, DMU3, DMU5, DMU7, and DMU8, will achieve efficiency in the next five years, as their scores will be higher than one number. Efficiency scores of DMU4 and DMU6 will be lower than one number in the next five years. The future average efficiency of each company is discovered based on the future efficiency scores. The empirical results show that six companies, including DMU1, DMU2, DMU3, DMU5, DMU7, and DMU8, will have an average performance with an average score above one number, and two companies, including DMU4 and DMU6, will not get the average efficiency because of their average score under one number. Comparing the average of these manufacturing companies in future time reveals that the best average efficiency will be DMU8 because its predicted efficiency scores will achieve the high values in the next five years. Besides, the average efficiency of DMU4 will be the lowest; thus, its operation process will not have an excellent result in the future time.

Table 6. Future Efficiency.

\begin{tabular}{|l|c|c|c|c|c|c|}
\hline DMUs & $\mathbf{2 0 2 1}$ & $\mathbf{2 0 2 2}$ & $\mathbf{2 0 2 3}$ & $\mathbf{2 0 2 4}$ & $\mathbf{2 0 2 5}$ & $\begin{array}{c}\text { Aver- } \\
\text { age }\end{array}$ \\
\hline $\mathrm{DMU}_{1}$ & 1.0783 & 1.0827 & 1.0858 & 1.0883 & 1.0880 & 1.0846 \\
\hline $\mathrm{DMU}_{2}$ & 1.0993 & 1.0969 & 1.0966 & 1.0968 & 1.0967 & 1.0973 \\
\hline $\mathrm{DMU}_{3}$ & 1.1338 & 1.1318 & 1.1287 & 1.1262 & 1.1271 & 1.1295 \\
\hline $\mathrm{DMU}_{4}$ & 0.7041 & 0.7003 & 0.6967 & 0.6950 & 0.6950 & 0.6982 \\
\hline $\mathrm{DMU}_{5}$ & 1.3578 & 1.3887 & 1.3935 & 1.3967 & 1.3945 & 1.3862 \\
\hline $\mathrm{DMU}_{6}$ & 0.7165 & 0.7198 & 0.7238 & 0.7289 & 0.7296 & 0.7237 \\
\hline $\mathrm{DMU}_{7}$ & 1.0567 & 1.0574 & 1.0573 & 1.0579 & 1.0581 & 1.0575 \\
\hline $\mathrm{DMU}_{8}$ & 3.3948 & 3.4020 & 3.4248 & 3.4501 & 3.4516 & 3.4247 \\
\hline
\end{tabular}

\section{DICUSSION}

A business or operational process of a manufacturing company is a set of activities to produce a specific product by transforming resources into finished goods. The manufacturers hold the costs of materials, labour, machines to transform materials into finished goods. An enterprise will have a high gross profit when its revenue deducts costs of manufacturing the product, such as total assets (costs of equipment, materials), equity, and liabilities. Therefore, we choose total assets, costs of revenues, and operating expenses to exhibit the input factors, and operating revenues and gross profit to represent the output factors. Calculating the ratio between inputs and outputs explores the efficiency scores of 8 manufacturing companies during the period 2016-2025, as shown in Table 3 and Table 6.

The empirical results denote that all efficiency scores of 8 manufacturing companies have a sharp variation in historical time and a slight change in future time. The efficiency score of DMU8 with a high deviation from 2.8453 to 4.1172 exhibits the largest change year by year in whole terms. Next, 
DMU5 has a large variation, and its efficiency scores increased sharply from 0.6820 in 2018 to 1.3852 in 2019, then always keeps over one number in next years and whole future terms. The remaining DMUs have a minor variation, as their efficiency scores under 1.3737 from past to future. From the average efficiency between historical and future terms, the average efficiency of most DMUs between historical and future terms has a low deviation except DMU5, as shown in Fig. (1). The difference change of average efficiency among historical period and future period for DMU1,DMU2, DMU3, DMU4, DMU5, DMU6, DMU7, and DMU8 is 0.03736; -0.061; $0.0766 ;-0.0454 ; 0.36834 ; 0.05202 ; 0.00462$; and 0.04942 , respectively. The empirical findings show that the average efficiency of three companies, including DMU2, DMU3, and DMU4 of the historical term, is higher than the future term; thus, they should make a plan to increase their efficiency score by reducing the costs of materials and costs of equipment and rising the value of a product. The average efficiency of remaining DMUs in the historical term is lower than in the future term, which is a good signal for their development process in the future.

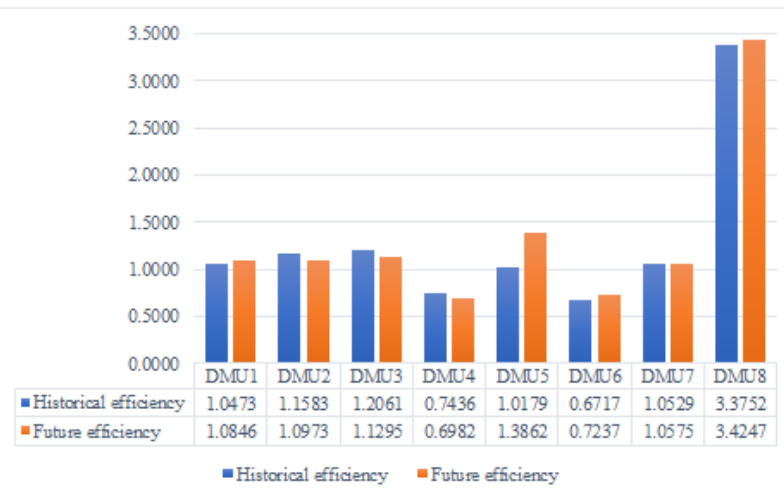

Fig. (1). The average efficiency between historical term and future term.

\section{CONCLUSION}

Manufacturing companies have a meaningful role in expanding and developing new products, which catch up with the customer's demand. The DEA approach measures their business results so that this study introduces the theoretical manufacturing industry, super-SBM model, and resampling model in the DEA method. Previous papers applied Partial Least Square s-Structural Equation Modelling and novel panel GMM model to study the manufacturing industry; however, these papers could not give the future values to create a development direction. Hence, this study applies the super-SBM and resampling models to evaluate the past, present, and forecast future performance. The proposed methods provide a reference for global manufacturing companies in future development strategies and competition.

Many previous studies usually integrate the DEA method with another method, such as the grey method or holt winter method, to observe and evaluate the performance from past to future. In this study, from the practical point of view, two models, namely the super-SBM model and resampling model in the DEA method, are used to conduct the efficiency score from past to future. First, the super-SBM model implements to measure the efficiency score in historical terms. Second, the resampling model with the function in forecasting and evaluating the efficiency score computes the future value of inputs and outputs for manufacturing companies and their future efficiency scores. Their efficiency scores are a valuable result to identify and determine the detailed performance that enterprises can know about their levels to improve future efficiency.

An evaluation of the manufacturing industry is a valuable reference for customers to know partners. The super-efficiency presents a separate performance for all DMUs so that the customer can discover the operational efficiency level to search for suitable partners. Customers can choose the excellent quality goods and the best providers.

This study measures the performance of 8 large manufacturing companies over the world by the integrations of the superSBM model and resampling model. The empirical findings reveal that the efficiency of Cardinal Health always gets and maintains at the highest level with an efficiency score above 2.8512 in the whole term. Other manufacturing companies have a soft fluctuation every year, and their scores are lower than 1.4944 from past to future. Besides, two manufacturing companies, including DMU4 and DMU6, should have a better strategy to improve their operational efficiency because their scores do not attain the standard efficiency in both historical and future terms. Most manufacturing companies are presenting a robust growth rate when based on actual and forecast performance indicators.

The super efficiency of the super-SBM model and the resampling model with the best function in measuring comparisons discover the efficiency score for each manufacturing company from past to future. The empirical findings conduct the efficiency scores of manufacturing companies through integrating the super-SBM model and the resampling model. As a result, manufacturing companies can determine and understand more about their operation; they can foresee their operational process term to create plans in the future time.

The study evaluates the performance of large manufacturing companies from past to future, but restrictions remain. First, variables such as number of employees, number of branches excluding the financial report of manufacturing companies are non-listed; thus, this study does not reflect depth and specification for the overall operation process. Further research should use more input and output factors to analyse the efficiency of a manufacturing company. Second, further study can update alternative models in the DEA method to compare and discover the change and difference of measuring the efficiency. Third, the information of several large manufacturing companies is not mentioned, which lacks comparison; therefore, future studies should seek more relative inputs and outputs of the remaining large manufacturing companies.

\section{ACKNOWLEDGEMENT}

The authors would like to thank the Editor and reviewers for their helpful comments. This study is supported by Thanh Dong University.

\section{CONFLICT OF INTEREST STATEMENT}

The authors declare that they have no conflict of interest. 


\section{APPENDIX}

Table A. Pearson Correlation in the Historical Term.

\begin{tabular}{|c|c|c|c|c|c|c|}
\hline Variable & Year & (I)TA & (I)CR & (I)OE & (O)OR & (O)GP \\
\hline (I)TA & \multirow{5}{*}{2016} & 1.0000 & 0.7829 & 0.4791 & 0.9424 & 0.6458 \\
\hline (I)CR & & 0.7829 & 1.0000 & -0.0158 & 0.8314 & 0.1676 \\
\hline (I)OE & & 0.4791 & -0.0158 & 1.0000 & 0.4040 & 0.7217 \\
\hline (O)OR & & 0.9424 & 0.8314 & 0.4040 & 1.0000 & 0.6868 \\
\hline$(\mathrm{O}) \mathrm{GP}$ & & 0.6458 & 0.1676 & 0.7217 & 0.6868 & 1.0000 \\
\hline (I)TA & \multirow{5}{*}{2017} & 1.0000 & 0.7398 & 0.5309 & 0.9045 & 0.5675 \\
\hline (I)CR & & 0.7398 & 1.0000 & 0.0507 & 0.7369 & 0.0512 \\
\hline (I)OE & & 0.5309 & 0.0507 & 1.0000 & 0.6340 & 0.8739 \\
\hline (O)OR & & 0.9045 & 0.7369 & 0.6340 & 1.0000 & 0.7124 \\
\hline$(\mathrm{O}) \mathrm{GP}$ & & 0.5675 & 0.0512 & 0.8739 & 0.7124 & 1.0000 \\
\hline (I)TA & \multirow{5}{*}{2018} & 1.0000 & 0.7563 & 0.6488 & 0.8844 & 0.5927 \\
\hline (I)CR & & 0.7563 & 1.0000 & 0.1263 & 0.7622 & 0.1707 \\
\hline (I)OE & & 0.6488 & 0.1263 & 1.0000 & 0.6613 & 0.8696 \\
\hline (O)OR & & 0.8844 & 0.7622 & 0.6613 & 1.0000 & 0.7676 \\
\hline$(\mathrm{O}) \mathrm{GP}$ & & 0.5927 & 0.1707 & 0.8696 & 0.7676 & 1.0000 \\
\hline (I)TA & \multirow{5}{*}{2019} & 1.0000 & 0.7485 & 0.6248 & 0.8369 & 0.5817 \\
\hline (I)CR & & 0.7485 & 1.0000 & 0.1952 & 0.8436 & 0.3006 \\
\hline (I)OE & & 0.6248 & 0.1952 & 1.0000 & 0.6023 & 0.8228 \\
\hline (O)OR & & 0.8369 & 0.8436 & 0.6023 & 1.0000 & 0.7653 \\
\hline (O)GP & & 0.5817 & 0.3006 & 0.8228 & 0.7653 & 1.0000 \\
\hline (I)TA & \multirow{5}{*}{2020} & 1.0000 & 0.6157 & 0.5987 & 0.6992 & 0.5302 \\
\hline (I)CR & & 0.6157 & 1.0000 & 0.2363 & 0.8584 & 0.3838 \\
\hline (I)OE & & 0.5987 & 0.2363 & 1.0000 & 0.6524 & 0.8902 \\
\hline (O)OR & & 0.6992 & 0.8584 & 0.6524 & 1.0000 & 0.8029 \\
\hline (O)GP & & 0.5302 & 0.3838 & 0.8902 & 0.8029 & 1.0000 \\
\hline
\end{tabular}

Table B. Pearson Correlation in the Future Term.

\begin{tabular}{|c|c|c|c|c|c|c|}
\hline Variable & Year & (I)TA & (I)CR & (I)OE & (O)OR & (O)GP \\
\hline (I)TA & \multirow{5}{*}{2021} & 1.0000 & 0.6157 & 0.5987 & 0.6992 & 0.5302 \\
\hline (I)CR & & 0.6157 & 1.0000 & 0.2363 & 0.8584 & 0.3838 \\
\hline (I)OE & & 0.5987 & 0.2363 & 1.0000 & 0.6524 & 0.8902 \\
\hline$(\mathrm{O}) \mathrm{OR}$ & & 0.6992 & 0.8584 & 0.6524 & 1.0000 & 0.8029 \\
\hline$(\mathrm{O}) \mathrm{GP}$ & & 0.5302 & 0.3838 & 0.8902 & 0.8029 & 1.0000 \\
\hline (I)TA & \multirow{3}{*}{2022} & 1.0000 & 0.7095 & 0.6165 & 0.8093 & 0.5740 \\
\hline (I)CR & & 0.7095 & 1.0000 & 0.1648 & 0.8265 & 0.2868 \\
\hline (I)OE & & 0.6165 & 0.1648 & 1.0000 & 0.6255 & 0.8680 \\
\hline
\end{tabular}

\begin{tabular}{|c|c|c|c|c|c|c|}
\hline (O)OR & & 0.8093 & 0.8265 & 0.6255 & 1.0000 & 0.7760 \\
\hline (O)GP & & 0.5740 & 0.2868 & 0.8680 & 0.7760 & 1.0000 \\
\hline (I)TA & \multirow{5}{*}{2023} & 1.0000 & 0.7048 & 0.6191 & 0.8026 & 0.5715 \\
\hline (I)CR & & 0.7048 & 1.0000 & 0.1751 & 0.8279 & 0.2939 \\
\hline (I)OE & & 0.6191 & 0.1751 & 1.0000 & 0.6327 & 0.8710 \\
\hline (O)OR & & 0.8026 & 0.8279 & 0.6327 & 1.0000 & 0.7792 \\
\hline (O)GP & & 0.5715 & 0.2939 & 0.8710 & 0.7792 & 1.0000 \\
\hline (I)TA & \multirow{5}{*}{2024} & 1.0000 & 0.7018 & 0.6194 & 0.7970 & 0.5693 \\
\hline (I)CR & & 0.7018 & 1.0000 & 0.1801 & 0.8311 & 0.3024 \\
\hline (I)OE & & 0.6194 & 0.1801 & 1.0000 & 0.6325 & 0.8703 \\
\hline (O)OR & & 0.7970 & 0.8311 & 0.6325 & 1.0000 & 0.7811 \\
\hline (O)GP & & 0.5693 & 0.3024 & 0.8703 & 0.7811 & 1.0000 \\
\hline (I)TA & \multirow{5}{*}{2025} & 1.0000 & 0.6983 & 0.6179 & 0.7926 & 0.5676 \\
\hline (I)CR & & 0.6983 & 1.0000 & 0.1822 & 0.8331 & 0.3068 \\
\hline (I)OE & & 0.6179 & 0.1822 & 1.0000 & 0.6320 & 0.8705 \\
\hline (O)OR & & 0.7926 & 0.8331 & 0.6320 & 1.0000 & 0.7818 \\
\hline (O)GP & & 0.5676 & 0.3068 & 0.8705 & 0.7818 & 1.0000 \\
\hline
\end{tabular}

\section{REFERENCES}

Alam, T., and Rastgi, R. 2019. Trend analysis of cost efficiency for the pharmaceutical industry: A DEA approach. Management Science Letters, 9(5), 749-754. Doi: 10.5267/j.msl.2019.1.014.

AlQershi, N., Abas, Z., and Mokhtar, S. 2021. The intervening effect of structural capital on the relationship between strategic innovation and manufacturing SMEs' performance in Yemen. Management Science Letters, 11(1), 21-30. Doi: 10.5267/j.msl.2020.8.034

Andersen, P., and Petersen, N.C. 1993. A Procedure for Ranking Efficient Units in Data Envelopment Analysis. Management Science, 39, 1261-1264. https://www.jstor.org/stable/2632964.

Banker, R. D., Charnes, A., \& Cooper, W. W. 1984. Some models for estimating technical and scale inefficiencies in data envelopment analysis. Management science, 30, 1078-1092. https://doi.org/10.1287/mnsc.30.9.1078.

Charnes, A., Cooper, W. W., and Rhodes, E. 1978. Measuring the efficiency of decision making units. European Journal of Operational Research, 2(6), 429-441. https://doi.org/10.1016/0377-2217(78)90138-8.

Chen X., Despeisse, M., and Johansson, B. 2020. Environmental Sustainability of Digitalization in Manufacturing: A Review. Sustainability, 12(24), 1-31. https://doi.org/10.3390/su122410298.

Chen, C. Y., Polemis, M., and Stengos, T. 2018. On the examination of nonlinear relationship between market structure and performance in the US manufacturing industry. Economics Letters, 164, 1-4. https://doi.org/10.1016/j.econlet.2017.12.030.

David, J. R., Richard, E.E., and Keeton, K. E. 2015. Open innovation at NASA: a new business model for advancing human health and performance innovations. Research-Technology Management, 5(3), 52-58. Doi: 10.5437/08956308X5803325.

Dwivedi, A., Agrawal, D., and Madaan, J. 2019. Sustainable manufacturing evaluation model focusing leather industries in India: A TISM approach. Journal of Science and Technology Policy Management, 10(2), 319-359. https://doi.org/10.1108/JSTPM-06-2018-0054.

Enyoghasi, C., \& Badurdeen, F. 2021. Industry 4.0 for sustainable manufacturing: Opportunities at the product, process, and system levels. Resources, Conservation and Recycling, 166, ID: 105362. https://doi.org/10.1016/j.resconrec.2020.105362.

Fajsi, A., Tekic, Z., and Moroca, S. 2016. Open innovation in manufacturing SMEs - integration into value networks. Proceedings of the 26th DAAAM International Symposium, Vienna, Austria. 1076-1081. Doi: $10.2507 / 26$ th.daaam.proceedings. 151 . 
Färe, R., and Lovell, C. A. K. 1978. Measuring the Technical Efficiency of product. Journal of Economic Theory, 19(1), 150-162. Doi: 10.1016/0022-0531(78)90060-1.

Feng, Z., Zeng, B., and Ming, Q. 2018. Environmental Regulation, Two-Way Foreign Direct Investment, and Green Innovation Efficiency in China's Manufacturing Industry. International Journal of Environmental Research and Public Health, 15(10), 1-22. https://doi.org/10.3390/ijerph15102292.

Freeman, O. 2020. Available online: https://www.manufacturingglobal.com/top10/top-10-largest-manufacturing-companies-world. (accessed on 10 February 2021)

Hsieh, J. C., Ma, L. H., and Chiu, Y. h. 2019. Assessing China's Use Efficiency of Water Resources from the Resampling Super Data Envelopment Analysis Approach. Water, 11, 115. https://doi.org/10.3390/w11051069

Huang, Y. S., and Liu, S. J. 2020. Efficiency evaluation of a sustainable hydrogen production scheme based on super efficiency SBM model. Journal of Cleaner Production, 256, 1-6. Doi: 10.1016/j.jclepro.2020.120447

Hu Kern, A., Schwarzmann, M., and Wiedenegger, A. 2012. Measuring the efficiency of English Premier League football: A two-stage data envelopment analysis approach. Sport, Business and Management, 2(3), 177-195. https://doi.org/10.1108/20426781211261502.

Le, T. 2020. Performance measures and metrics in a supply chain environment. Uncertain Supply Chain Management, 8(1), 93-104. Doi: 10.5267/j.uscm.2019.8.003.

Lia, X. Z. 2011. Upgrading of China's Manufacturing Industry: Two-sector Analysis Based on the Facilitation of Producer Services. Procedia Environmental Sciences, 10, 307-312. https://doi.org/10.1016/j.proenv.2011.09.050.

Nguyen, X. H., and Nguyen, T. K. L. 2021. Approaching the Negative SuperSBM Model to Partner Selection of Vietnamese Securities Companies. The Journal of Asian Finance, Economics and Business, 8(3), 527-538. https://doi.org/10.13106/jafeb.2021.vol8.no3.0527.
Oliver Freeman. Avaible online: https://www.manufacturingglobal.com/top10/top-10-largest-manufacturing-companies-world (Accessed on 15 February 2021).

Shen, Y., Bao, Q., and Hermans, E. 2020. Applying an Alternative Approach for Assessing Sustainable Road Transport: A Benchmarking Analysis on EU Countries. Sustainability, 12(24), 1-16. https://doi.org/10.3390/su122410391.

Tmxmoney. Available online: https://money.tmx.com/en (accessed on 15 February 2021).

Tone, K. 2002. A slacks-based measure of super-efficiency in data envelopment analysis. European Journal of Operational Research, 143, 32 41. https://doi.org/10.1016/S0377-2217(01)00324-1.

Tone, K. and Ouenniche, J. 2016. DEA Scores' Confidence Intervals with Past-Present and Past-Present-Future Based Resampling. American Journal of Operations Research, 6(12), 121-135. Doi: 10.4236/ajor.2016.62015

Tu, K. J. 2015. Establishing the DEA energy management system for individual departments within universities. Facilities, 33 (11/12), 716735. https://doi.org/10.1108/F-11-2014-0092.

Wang, C. N., Peng, Y. C., Hsueh, M. H., and Wang, Y. H. 2021. The Selection of Strategic Alliance in IC Packaging and Testing Industry with DEA Resampling Comparative Evaluation. Applied Sciences, 11(1), 1-18. https://doi.org/10.3390/app11010204.

Wang, C. N., and Le, A. L. 2018. Measuring the Macroeconomic Performance among Developed Countries and Asian Developing Countries: Past, Present, and Future. Sustainability, 10, 1-18. https://doi.org/10.3390/su10103664.

Zhang, G., and Lee, Y. 2021. Determinants of Financial Performance in China's Intelligent Manufacturing Industry: Innovation and Liquidity. International Journal of Financial Studies, 9(1), 1-19. https://doi.org/10.3390/ijfs9010015

Copyright $@$ 2021- All Rights Reserved

This is an open-access article. 